\title{
Host adaptation of bovine Staphylococcus aureus seems associated with bacteriological cure after lactational antimicrobial treatment
}

\author{
B. H. P. van den Borne, ${ }^{* 1}$ M. Nielen, ${ }^{*}$ G. van Schaik, † M. B. Melchior, $\ddagger$ T. J. G. M. Lam, $§$ and R. N. Zadoks\# $\|$ \\ ${ }^{\star}$ Faculty of Veterinary Medicine, Utrecht University, Yalelaan 7, 3584 CL Utrecht, the Netherlands \\ †GD Animal Health Service, PO Box 9, 7400 AA Deventer, the Netherlands \\ †Central Veterinary Institute (CVI), Wageningen UR, PO Box 2004, 8203 AA Lelystad, the Netherlands \\ $\S$ Dutch Udder Health Centre, PO Box 2030, 7420 AA Deventer, the Netherlands \\ \#Moredun Research Institute, Pentlands Science Park, Bush Loan, Penicuik, EH26 OPZ, United Kingdom \\ ||Royal (Dick) School of Veterinary Studies, University of Edinburgh, Roslin, EH25 9RG, United Kingdom
}

\begin{abstract}
Staphylococcus aureus causes a wide range of diseases in multiple species. Some sequence types (ST) are observed in a variety of hosts, whereas other strains are mainly associated with bovine mastitis, suggesting host adaptation. We propose that host adaptation of Staph. aureus may influence bacteriological cure of bovine subclinical mastitis after antimicrobial treatment. To test this hypothesis, multilocus sequence typing was performed on Staph. aureus isolates from 60 treated and 79 untreated control quarters that were obtained from well-defined cohorts of dairy cows from a recently conducted randomized field trial on early treatment of subclinical mastitis. Bovine-associated ST were distinguished from non-bovine-associated ST based on the literature and public databases. The association between host adaptation and bacteriological cure was investigated using population-averaged logistic regression models. Thirteen ST were identified, with approximately $80 \%$ of isolates belonging to bovine-associated $\mathrm{ST}$. The odds for cure were around 2.5 times as high for non-bovine-associated ST as for bovine ST in treated quarters, whereas no difference in spontaneous cure was observed in untreated control quarters. In addition, host adaptation was related to known predictors of cure, such as penicillin susceptibility and somatic cell count. All isolates belonging to non-bovine-associated ST were resistant to penicillin, whereas the majority of isolates belonging to bovine-associated ST were penicillin susceptible. Penicillin-resistant bovine-associated strains were associated with high somatic cell counts compared with other strains. The correlation between penicillin resistance, cell counts, and host adaptation may affect the association between host adaptation and cure. For diagnostic purposes, a simple and fast alter-
\end{abstract}

Received December 4, 2009.

Accepted March 1, 2010.

${ }^{1}$ Corresponding author: b.vandenborne@uu.nl native to multilocus sequence typing of Staph. aureus to determine host adaptation may be valuable.

Key words: Staphylococcus aureus, subclinical mastitis, antimicrobial treatment, genotyping

\section{INTRODUCTION}

Staphylococcus aureus is an important pathogen of humans and animals. Staphylococcus aureus is a major cause of mastitis in dairy cattle and is associated with economic losses worldwide (Halasa et al., 2007).

Molecular typing studies provide evidence for adaptation of Staph. aureus to different hosts. Some sequence types (ST) such as ST398 are found in many host species, including humans and animals (Weese and van Duijkeren, 2010), whereas other types of Staph. aureus are specifically associated with animals (Sung et al., 2008; Ikawaty et al., 2009; Lowder et al., 2009). Bovineassociated Staph. aureus diverged from a common ancestor that resembled human-associated Staph. aureus clones and is now distinct from strains that are found in human infections (Herron-Olson et al., 2007). Furthermore, ruminant-associated strains differ from those associated with other species such as rabbits or poultry (Ben Zakour et al., 2008; Alves et al., 2009; Smyth et al., 2009). Some typing studies provide evidence for tissue adaptation within host species; for example, to skin or mammary gland tissue (Fitzgerald et al., 2001a; Zadoks et al., 2002), whereas other results suggest host rather than tissue specificity (Alves et al., 2009).

Bovine Staph. aureus strains may differ in virulence as evident in clinical signs (Zadoks et al., 2000; Haveri et al., 2007), SCC (Zadoks et al., 2000; Graber et al., 2009), or milk production losses (Middleton and Fox, 2002). The Staph. aureus genome consists of a core genome and a variable genome that includes mobile genetic elements (MGE; Lindsay et al., 2006). Virulence of strains is believed to be encoded by toxin or resistance genes located on MGE (Fitzgerald et al., 2001b; Sung et al., 2008) such as plasmids, phages, pathogenicity islands, and genomic islands. One of the 
virulence factors, insertion sequence 257 (IS257 or its homolog IS431), is associated with penicillin resistance (Yazdankhah et al., 2000; Olsen et al., 2006) and occurs in multiple locations within the Staph. aureus genome (Cocchiaro et al., 2006; Olsen et al., 2006; Baba et al., 2008).

Treatment of Staph. aureus subclinical mastitis (SCM) with antimicrobials has been advocated as a means to cure a cow and to decrease infectious pressure within the herd (Barkema et al., 2006). Results of treatment are highly variable in dairy practice and generally disappointing (Sol et al., 1997; Deluyker et al., 2005; Sandgren et al., 2008), although early detection and treatment of Staph. aureus SCM seems to improve the probability of cure (Barkema et al., 2006; van den Borne et al., 2010). In addition to host factors, pathogen factors are thought to affect cure of Staph. aureus infections (Barkema et al., 2006). Strain-specific cure probabilities have been observed at drying off (Dingwell et al., 2006), in clinical mastitis (Haveri et al., 2007), and in humans (Campbell et al., 2008; Lalani et al., 2008; Bae et al., 2009). Currently, there are no diagnostic markers at strain level, other than penicillin resistance, that indicate the probability of cure after lactational treatment of Staph. aureus SCM (Barkema et al., 2006).

The main goal of this study was to determine whether host adaptation of bovine Staph. aureus, as determined by multilocus sequence typing (MLST), is associated with bacteriological cure of recently acquired SCM during lactation, with or without antimicrobial treatment. Furthermore, the association between Staph. aureus host adaptation and known predictors for cure (i.e., penicillin susceptibility and SCC) was analyzed. The usefulness of insertion sequence IS257 as a predictor for host adaptation of Staph. aureus or bacteriological cure of SCM was also examined.

\section{MATERIALS AND METHODS}

\section{Sample Collection and Definitions}

Bacterial isolates were obtained from a field study on antimicrobial treatment of recently acquired SCM (van den Borne et al., 2010). Briefly, the field study was performed from December 2006 to May 2008 in 39 Dutch dairy herds that had a high incidence of SCM and participated in four-weekly milk recording. Quarter milk samples were aseptically collected within $10 \mathrm{~d}$ after the milk recording from cows with a first elevated composite SCC (CSCC; $\geq 250,000$ cells/mL for multiparous cows and $\geq 150,000$ cells/mL for primiparous cows) after 2 consecutive CSCC measurements below the parity-specific thresholds. Bacteriological culture, quarter SCC (QSCC) determination of all samples, and $\beta$-lactamase production testing of Staph. aureus isolates were performed within $24 \mathrm{~h}$ of sampling. To mimic use of SCC and culture data in dairy practice in the Netherlands, quarters with a single Staph. aureus culture-positive sample and a QSCC $\geq 100,000$ cells $/ \mathrm{mL}$ were randomly assigned at cow level to antimicrobial treatment or to an untreated control group. Enrolled cows could have multiple quarters infected with Staph. aureus. Farmers treated cows intramammarily according to their own treatment protocols with commercially available antimicrobial products. Quarters with Staph. aureus strains that were $\beta$-lactamase-positive were treated with non- $\beta$-lactam antimicrobials; quarters with $\beta$-lactamase-negative strains could be treated with any compound (i.e., $\beta$-lactam or non- $\beta$-lactam antimicrobials). If CSCC of untreated cows was still above the parity-specific CSCC threshold at the next milk recording, quarter milk sampling and laboratory tests were repeated and cows with Staph. aureus positive quarters were allocated to treatment and control groups as described. Milk samples from all treated and control quarters were taken to determine bacteriological status 21 and $28 \mathrm{~d}$ after treatment allocation. Staphylococcus aureus-positive quarters were defined to be cured when Staph. aureus was absent from both samples post-intervention. Change of phenotypic penicillin susceptibility from pre- to post-intervention was also defined as cure $(\mathrm{n}=2)$. Staphylococcus aureus isolates from quarters of enrolled cows were stored at $-70^{\circ} \mathrm{C}$ until genotyping was performed.

\section{Genotyping}

Genotyping of isolates, using MLST, was performed using standard protocols (Enright et al., 2000). Forward and reverse trace files of a novel allele and novel allelic profiles were sent to the database curator for allele and ST assignment and submission to the MLST database (www.mlst.net). Alleles, ST, and clonal complexes (CC; groups of closely related ST) were assigned using the MLST database. Bovine-associated CC were distinguished from $\mathrm{CC}$ associated with other hosts based on the MLST database and literature (ArmandLefevre et al., 2005; Smith et al., 2005b; Aires-de-Sousa et al., 2007; Rabello et al., 2007; Cuny et al., 2008; Deurenberg and Stobberingh, 2008; Ikawaty et al., 2009; Walther et al., 2009; Hasman et al., 2010; Weese and van Duijkeren, 2010). Clonal complexes were defined to be bovine adapted if isolates belonging to those $\mathrm{CC}$ were frequently found in milk samples, and included CC50, CC97, CC151, and CC479. Those CC frequently reported in samples from nonbovine hosts were defined to be non-bovine-associated. 
Presence of IS257 was determined as described (Sidhu et al., 2002) with slight modifications. Primers based on the whole-genome sequence of Staph. aureus bovine reference strain RF122 (Fitzgerald et al., 1997; Herron-Olson et al., 2007) were developed by Melchior (2007) (901F: 5'-GTTTGGTTCGAAAGCGAGAG-3' and 902R: 5'-TTCAACGAAGGTTGCAATGA-3') to identify the presence of the IS257 gene flanking the glycosyltransferase gene.

Isolates belonging to ST398 were tested for presence of the mecA gene (de Neeling et al., 1998).

\section{Statistical Analysis}

Sequence type, IS257 presence, and $\beta$-lactamase production could be determined for 1 or 2 isolates per quarter before treatment allocation, depending on the number of available isolates. For example, for a cow that was treated after the first culture-positive sample, only 1 isolate was analyzed. For a cow that was allocated to the control group after the first culture-positive sample, a second positive sample might be available. When 2 culture-positive samples were available from a quarter before final treatment allocation, strain characteristics of the second isolate only were used for statistical analysis.

Crude (i.e., not corrected for other factors) cure rates for treated and control quarters were determined for each CC. Quarters with 1 or 2 culture-positive samples before treatment allocation, respectively, were analyzed separately within each CC. The relation between host adaptation and bacteriological cure was investigated using univariable $\chi^{2}$ tests for treated and control quarters. For treated quarters, a multivariable population-averaged logistic regression model for bacteriological cure was built to determine its relation with host adaptation and the number of culture-positive samples before treatment allocation. The number of culture-positive samples before treatment allocation was forced into the model to test whether early treatment improved cure as observed in our previous study (van den Borne et al., 2010). A population-averaged cluster effect at the cow level was added to the model to correct for correlation of multiple infected quarters within cows and to report these effects across cows rather than in specific cows. The same method was used to test whether IS257 presence next to the glycosyltransferase gene was related to bacteriological cure.

Chi-squared tests were used to investigate the association between host adaptation and penicillin susceptibility, between penicillin susceptibility and presence of IS25\%, and between host adaptation and presence of IS25\%.
The linear score of QSCC before treatment allocation (LSQSCC; Shook, 1993) was determined in quarters with 2 culture-positive samples before treatment allocation. The association between LSQSCC and strain type was investigated using population-averaged linear regression models for the first and second culture-positive sample, respectively, with clustering at the cow level. For this analysis, 3 categories of strains were distinguishedbovine-associated penicillin resistant, bovine-associated penicillin susceptible, and non-bovine-associated. This model was also used to investigate the relation between LSQSCC and presence of IS25\%.

All statistical analyses were performed using PROC FREQ and PROC GENMOD in SAS 9.1 (SAS Institute Inc., Cary, NC). Statistical significance was set at $P<0.05$.

\section{RESULTS}

Sequence type and IS257 information was available for 207 isolates, and complete information on bacteriological cure was available for 166 isolates from 139 quarters of 119 cows in 31 herds. The median number of cows per herd represented by strains in the collection was 2 , ranging from 1 to 28 . Other isolates $(n=41)$ could not be associated with cure because the quarter was enrolled without fulfilling the inclusion criteria $(\mathrm{n}=20)$, no follow-up information was available (e.g., because of culling or dry off; $n=14$ ) or the cow was treated for clinical mastitis in that $(\mathrm{n}=3)$ or another quarter ( $\mathrm{n}$ $=4$ ). Loss to follow-up did not differ between CC and between bovine- and non-bovine-associated strains.

\section{MLST}

The distribution of ST and CC of isolates from quarters with recently acquired SCM is presented in Table 1. Thirteen ST were observed, belonging to $8 \mathrm{CC}$, with 3 new ST identified. Approximately $20 \%$ of the isolates belonged to CC (CC1, CC8, CC9, and CC398) not previously associated with bovine mastitis (Smith et al., 2005b; Aires-de-Sousa et al., 2007; Rabello et al., 2007; Hasman et al., 2009; Ikawaty et al., 2009). All 34 ST50 isolates were identified in a single herd and this ST was widespread within the herd: 34 out of 40 quarters from which isolates were genotyped were positive for ST50 Staph. aureus in this herd. Four quarters from 3 cows on 1 farm had ST398, and all ST398 isolates were $m e c A$-negative. Bovine-associated strains were isolated on more farms (median $=2$, range $1-15)$ than non-bovine-associated strains (median $=1$, range $1-3$ ). Penicillin susceptibility was available from isolates of 49 quarters with 2 culture-positive samples before treat- 
Table 1. Frequency of sequence types identified by multilocus sequence typing for isolates belonging to quarters with 1 or 2 culture-positive samples before treatment allocation, their corresponding clonal complex (CC), ${ }^{1}$ herd of origin, and number of insertion sequence IS25\%-positive and phenotypically penicillin-resistant isolates, according to host adaptation

\begin{tabular}{|c|c|c|c|c|c|c|c|c|c|}
\hline \multirow[b]{2}{*}{ Sequence type } & \multirow[b]{2}{*}{$\mathrm{CC}$} & \multicolumn{2}{|c|}{$\begin{array}{l}\text { One positive } \\
\text { sample }\end{array}$} & \multicolumn{2}{|c|}{$\begin{array}{l}\text { Two positive } \\
\text { samples }\end{array}$} & \multirow[b]{2}{*}{ Herd of origin } & \multirow[b]{2}{*}{ Total } & \multirow{2}{*}{$\begin{array}{l}\text { IS25\%- } \\
\text { positive }\end{array}$} & \multirow{2}{*}{$\begin{array}{l}\text { Penicillin- } \\
\text { resistant }\end{array}$} \\
\hline & & $\mathrm{n}$ & $\%$ & $\mathrm{n}$ & $\%$ & & & & \\
\hline 1 & 1 & 1 & 1.1 & - & - & 31 & 1 & - & 1 \\
\hline 8 & 8 & 8 & 8.9 & 4 & 8.2 & $2,25,35$ & 12 & - & 12 \\
\hline 9 & 9 & 2 & 2.2 & 5 & 10.2 & $12,16,22$ & 7 & - & 7 \\
\hline Subtotal & & 15 & 16.7 & 11 & 22.4 & & 26 & 0 & 26 \\
\hline \multicolumn{10}{|c|}{ Bovine-associated strains } \\
\hline 50 & 50 & 21 & 23.3 & 13 & 26.5 & 13 & 34 & - & - \\
\hline 71 & 97 & 3 & 3.3 & - & - & 40 & 3 & - & - \\
\hline 124 & 97 & 2 & 2.2 & 5 & 10.2 & 26,41 & 7 & - & 7 \\
\hline 151 & 151 & 5 & 5.6 & 1 & 2.0 & $7,9,25,36$ & 6 & 6 & - \\
\hline Subtotal & & 75 & 83.3 & 38 & 77.6 & & 113 & 37 & 7 \\
\hline Total & & 90 & 100 & 49 & 100 & & 139 & 37 & 33 \\
\hline
\end{tabular}

${ }^{1}$ According to www.mlst.net.

${ }^{2}$ New sequence type.

ment allocation, whereas ST and IS257 information before treatment allocation was available from isolates from 27 quarters. One quarter yielded 2 isolates with different phenotypic penicillin susceptibilities, whereas ST and IS257 detection did not differ between the 2 isolates before treatment allocation.

Clonal complex-specific crude cure rates of quarters with 1 or 2 culture-positive samples before treatment allocation are given in Table 2 for treated and control quarters, respectively. Crude bacteriological cure of non-bovine-associated strains was numerically higher after treatment $[(4+4) /(5+6)=72.7 \%]$ compared with bovine-associated strains $[(18+8) /(32+17)=$ $53.1 \% ; P=0.23)$. Crude bacteriological cure of untreated control quarters was $13.3 \%[(2+0) /(10+5)]$ and $14.1 \%[(7+2) /(43+21)]$, respectively $(P=0.94)$.

Bacteriological cure after antimicrobial treatment of non-bovine-associated strains was higher than for bovine-associated strains [odds ratio $(\mathbf{O R})=2.57$; 95\% CI: $0.59-11.20$ ] in a population-averaged logistic regression model $(P=0.21)$. Bacteriological cure did not differ between quarters with 1 or 2 Staph. aureus culture-positive samples before treatment allocation $(\mathrm{OR}=1.48 ; 95 \%$ CI: $0.59-3.74 ; P=0.41)$.

\section{IS257 Typing}

Thirty-seven Staph. aureus isolates were IS25\%-positive and all belonged to CC151 (Table 1). Crude cure rate after treatment did not differ between IS25\%-positive strains $[(5+2) /(9+5)=50 \%]$ and IS25\%-negative strains $[(22-5+12-2) /(37-9+23-5)=58.7 \% ; P=0.57$; Table 2]. In control quarters, crude cure rates also did not differ between IS25\%-positive strains $[(4+0) /(17+6)$ $=17.4 \%]$ and IS25\%-negative strains $[(9-4+2-0) /$ $(53-17+26-6)=12.5 \% ; P=0.57]$.

Presence of IS257 was not associated with bacteriological cure $(\mathrm{OR}=0.95 ; 95 \% \mathrm{CI}: 0.27-3.34 ; P=0.94)$ in a population-averaged logistic regression model, and again no difference was observed between quarters with 1 or 2 culture-positive samples before treatment allocation $(\mathrm{OR}=1.32 ; 95 \% \mathrm{CI}: 0.51-3.44 ; P=0.57)$.

\section{Penicillin Resistance}

All non-bovine-associated isolates were penicillin resistant and originated from 8 farms (Table 1). Bovine-associated penicillin-resistant isolates $(\mathrm{n}=7)$ were limited to ST124 (CC97) and originated from 2 farms. All IS25\%-positive strains (CC151) were penicillin sensitive.

\section{QSCC}

The distribution of LSQSCC for 3 categories of strains is shown in Figure 1 for quarters with 2 culturepositive samples before treatment allocation. Based on population-averaged linear regression models, bovine- 
Table 2. Crude bacteriological cure (in numbers and percentages) of quarters with isolates belonging to bovine- and non-bovine-associated clonal complexes in treated and control quarters with subclinical Staphylococcus aureus mastitis for 1 or 2 culture-positive samples before treatment allocation

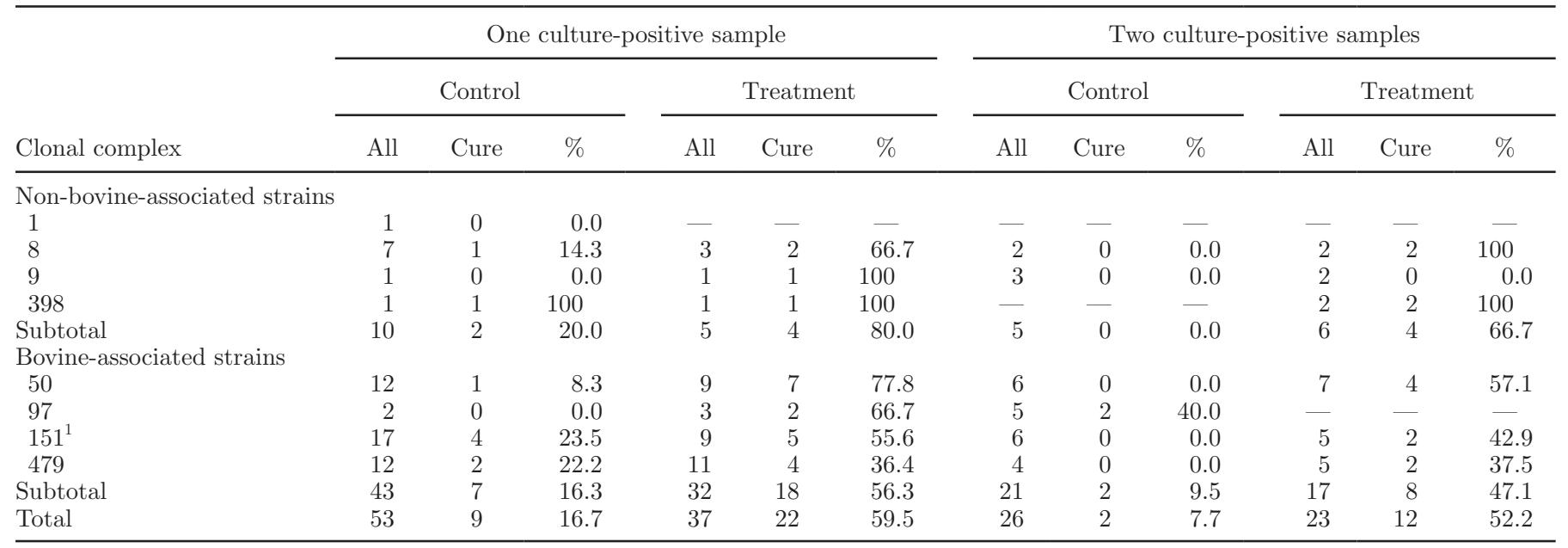

${ }^{1}$ All isolates were insertion sequence IS25\%-positive.

associated penicillin-resistant Staph. aureus strains had higher LSQSCC than other strains in both the first and second culture-positive samples $(P<0.0001)$.

No significant difference in host response, as reflected by LSQSCC, between IS25\%-positive and IS25\%-negative strains was observed at either the first $(P=0.36)$ or second $(P=0.33)$ culture-positive sample.

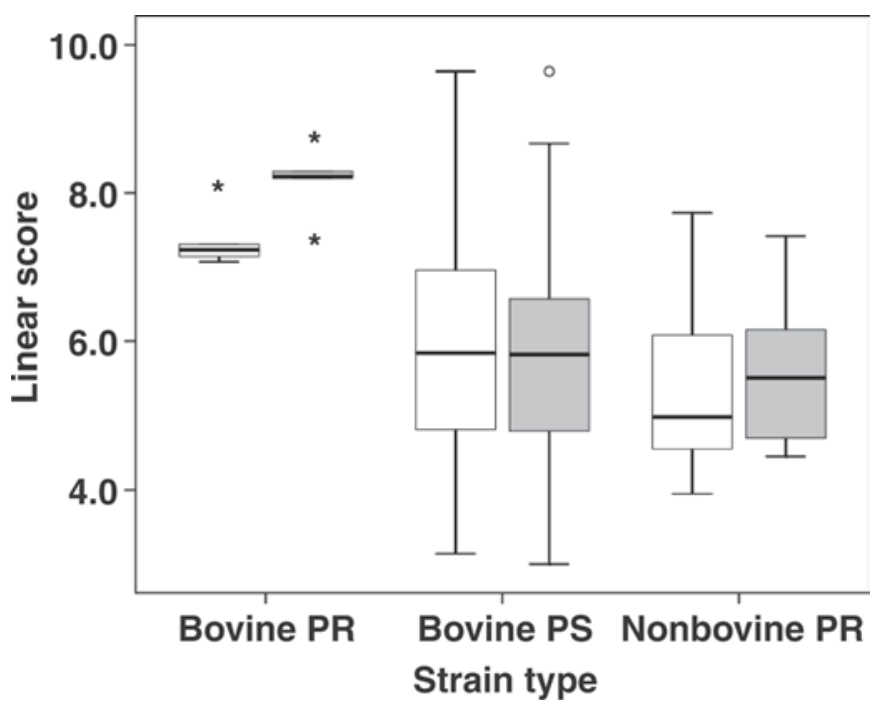

Figure 1. Linear score of quarter SCC before intervention at the first (white bars) or second (gray bars) culture-positive sample for Staphylococcus aureus strains categorized by host-adaptation and penicillin susceptibility, in quarters $(\mathrm{n}=49)$ with 2 culture-positive samples. $\mathrm{PS}=$ penicillin-sensitive $; \mathrm{PR}=$ penicillin-resistant.

\section{DISCUSSION}

It was hypothesized that bacteriological cure of Staph. aureus strains is associated with host adaptation and that presence of IS257 might be used as an indicator for host adaptation and bacteriological cure. Results from the current study, using isolates from well-defined cohorts of dairy cows from a randomized field trial, seem to support the first hypothesis but not the second. Bovine-associated Staph. aureus strains had a nonsignificant but clinically important lower bacteriological cure after antimicrobial treatment compared with non-bovine-associated strains. Treatment was according to farmers' treatment protocols, which differentiated between $\beta$-lactam-positive and $\beta$-lactam-negative strains, and bacteriological cure did not differ between therapies in our previous study (van den Borne et al., 2010). Strain-specific Staph. aureus cure rates have previously been determined at drying off (Dingwell et al., 2006), in clinical mastitis (Haveri et al., 2007) and in humans (Campbell et al., 2008; Lalani et al., 2008; Bae et al., 2009). Our results suggest that determination of Staph. aureus host adaptation has value in predicting bacteriological cure after antimicrobial treatment during lactation and could be used to guide treatment and management decisions in dairy practice, together with information on cow characteristics (Sol et al., 1997; Deluyker et al., 2005; Barkema et al., 2006; Sandgren et al., 2008). Specifically, to achieve good probabilities of cure, treatment duration for bovine-associated strains may need to be longer compared with that for nonbovine-associated strains. Although treatment is often considered to be of limited value in control of Staph. aureus problems, bacteriological cure of recently acquired 
subclinical Staph. aureus was much higher in quarters treated early than in untreated control quarters.

Staphylococcus aureus genotypes can be associated with clinical or epidemiological characteristics such as persistence (Smith et al., 2005a), within-herd prevalence and SCC (Zadoks et al., 2000; Graber et al., 2009), milk production (Middleton and Fox, 2002), and severity of mastitis (Zadoks et al., 2000; Haveri et al., 2007). In our study, quarters with bovine-associated penicillinresistant strains were more likely to have high SCC than quarters with other Staph. aureus strains. Other clinical characteristics were not evaluated.

Most ST and CC identified in this study have been previously isolated from cases of bovine Staph. aureus mastitis. Some CC occur worldwide (Fitzgerald et al., 1997; Smith et al., 2005b), whereas others may have a local or regional distribution (Guidry et al., 1998; Capurro et al., 2010). Clonal complex CC97 was frequently identified among isolates from Brazil (Airesde-Sousa et al., 2007; Rabello et al., 2007), and the United Kingdom, United States, and Chile (Smith et al., 2005b), but was uncommon in bulk milk samples from Norway (Jørgensen et al., 2005). A common Staph. aureus strain identified in Ireland and the United States (Fitzgerald et al., 1997), later identified to be CC151 (Herron-Olson et al., 2007), was observed in our study and another study from the Netherlands (Ikawaty et al., 2009). Clonal complex CC479 was also common in that study (Ikawaty et al., 2009), as well as in our study. We identified ST50 in a single herd with high Staph. aureus prevalence; ST50 has not been described in the Netherlands before (Ikawaty et al., 2009), but it was identified, albeit at a low prevalence, in a study of a large collection of intercontinental bovine isolates (Smith et al., 2005b). This ST was also widely disseminated among Danish dairy herds in contrast to Danish pig and poultry farms (Hasman et al., 2010). The Danish isolates were $s p a$-typed and subsequently their ST was determined on representative isolates from each spa type (Hasman et al., 2010). Although spa type and ST are not necessarily congruent (Ikawaty et al., 2009), CC50 was defined to be bovine-associated. Clonal complexes CC1, CC8, and CC9 together comprised most of the non-bovine-associated isolates in our study. They have rarely been identified in bovine milk samples (Smith et al., 2005b; Rabello et al., 2007; Hasman et al., 2010) but are frequently found in humans (www. mlst.net; Deurenberg and Stobberingh, 2008). Clonal complexes CC1 and CC8 were also observed in methicillin-resistant Staph. aureus (MRSA)-positive horses (Cuny et al., 2008; Walther et al., 2009), whereas CC9 was identified in pigs and pig farmers (Armand-Lefevre et al., 2005).
Animal ST398 is considered a potential problem for human health care (van Loo et al., 2007; Deurenberg and Stobberingh, 2008) because it is associated with methicillin resistance (Weese and van Duijkeren, 2010). In addition, ST398 has the ability to acquire virulence genes from other, more pathogenic MRSA strains by horizontal gene transfer (van Belkum et al., 2008). Methicillin-susceptible ST398 Staph. aureus has been described before (Armand-Lefevre et al., 2005; van Belkum et al., 2008). In our study, all ST398 Staph. aureus isolates were mecA-negative, showing that detection of ST398 does not necessarily imply MRSA presence in a dairy herd. Furthermore, all ST398-positive quarters (n $=4$ ) cured, despite penicillin resistance of the isolates and despite inclusion of one quarter in the untreated control group.

All non-bovine-associated strains were penicillin resistant, whereas among the bovine-associated strains, penicillin resistance was limited to ST124 (CC97). In a study on Streptococcus agalactiae (Dogan et al., 2005), another important mastitis pathogen, human isolates were more likely than bovine isolates to test positive for antimicrobial resistance. Penicillin resistance is generally associated with decreased Staph. aureus cure rates (Sol et al., 1997; Barkema et al., 2006), but a relatively high cure rate for penicillin-resistant strains was observed in our study on early treatment of Staph. aureus mastitis (van den Borne et al., 2010). The current study suggests that penicillin resistance is correlated with non-bovine-associated strains, which may explain high, rather than low, probabilities of cure. Theoretically, 4 categories of strains may be distinguished: bovine-associated penicillin resistant, bovine-associated penicillin sensitive, non-bovine-associated penicillin resistant, and non-bovine-associated penicillin sensitive. These combinations would be expected to have low, intermediate, intermediate, and high probabilities of cure, respectively. The number of bovine-associated penicillin-resistant isolates in the current investigation was too small to test whether penicillin susceptibility affected bacteriological cure after antimicrobial treatment within bovine-associated strains. However, SCC is an important host immune response predicting bacteriological cure (Sol et al., 1997; Barkema et al., 2006; Sandgren et al., 2008), and LSQSCC was higher for bovine-associated penicillin-resistant strains than for bovine-associated penicillin-sensitive strains or for nonbovine-associated strains. Preferential culling of cows with high CSCC in the study herds may explain why few bovine-associated penicillin-resistant isolates were obtained. The absence of non-bovine-associated penicillin-sensitive isolates in the current study might be because of their low ability to infect mammary tissue, 
resulting in low prevalence, or because of low virulence, resulting in a low host immune response. Some chronic Staph. aureus infections are not associated with elevated SCC (Zadoks et al., 2000), and those infections would have been excluded from our study based on cow SCC criteria. In addition to the core bacterial genome, as characterized by MLST in the current study, virulence genes located on MGE such as pvl, blaZ, lukM, sed, and sej (Haveri et al., 2007; Campbell et al., 2008; Lalani et al., 2008; Bae et al., 2009) may affect bacteriological cure after treatment. Molecular typing data from additional treatment trials would be needed for further evaluation of the role of the core and accessory genome in treatment response.

Presence of $I S 257$ next to the glycosyltransferase gene was only observed in isolates belonging to CC151 when using location-specific primers that were developed based on the available whole-genome sequence from bovine Staph. aureus reference strain RF122, which belongs to ST151 (Fitzgerald et al., 1997; Herron-Olson et al., 2007). Because bovine-associated CC50, CC97, and CC479 were IS25\%-negative at that particular place in the genome, these primers cannot be used as a marker to discriminate between bovine-associated (CC50, CC97, CC151, and CC479) and non-bovine-associated strains. The whole-genome sequence project identified additional genes to be limited to bovine Staph. aureus (Herron-Olson et al., 2007). Such genes may act as markers for host adaptation, but further research on a larger number of isolates is needed to determine their potential value as diagnostic tools.

Staphylococcus aureus strains were classified as bovine- or non-bovine-associated strains based on the reported frequency of isolates belonging to specified ST and CC in the MLST database and the literature. The current literature needed to be considered because the distribution of isolates in the MLST database is not representative for the animal Staph. aureus population. The database consists predominantly of isolates from humans. If bovine isolates are included, often only one isolate per ST is included as representative for that ST, regardless of the number of animals, herds, or countries from which the ST was identified. Furthermore, animal isolates in the database may be clustered (e.g., longitudinal samplings on the same animal in the same herd). Comparing peer-reviewed publications on MLST of bovine Staph. aureus to the database, it was clear that many genotyped isolates are not submitted to the database. Therefore, epidemiological information that was essential for interpretation of the MLST database at animal population level is missing.

The current study had some limitations. First, it was limited by the relatively small number of treated quarters, leading to low statistical power. Our findings can be considered pilot data for future studies using greater numbers of isolates and molecular techniques with more discriminatory power (e.g., micro-array and whole-genome sequencing; Herron-Olson et al., 2007; Sung et al., 2008). Also, the frequency of MLST and IS257 genotypes in our study may not truly represent the Dutch distribution of Staph. aureus genotypes because isolates were collected from selected herds with a high SCM incidence in a certain geographical region of the Netherlands. Additionally, in the current study, only genotyping and phenotyping of isolates was performed, whereas function or expression of genes was not investigated. Despite these limitations, the estimates were unbiased because Staph. aureus genotypic and phenotypic information was available from isolates from a randomized field study on well-defined cohorts of cows with recently acquired SCM in 39 Dutch dairy herds. Also, the results from the current study can be applied to other countries because standardized laboratory techniques (PCR and sequencing) were used to characterize Staph. aureus isolates, and some ST identified in our collection occur worldwide (Fitzgerald et al., 1997; Smith et al., 2005b).

\section{CONCLUSIONS}

Host adaptation of recently acquired bovine Staph. aureus SCM isolates seems to be associated with bacteriological cure after lactational antimicrobial treatment. Non-bovine-associated strains had a higher probability of cure after treatment compared with bovine-associated strains, whereas presence of IS257 was not associated with bacteriological cure. A higher frequency of penicillin resistance was observed in nonbovine-associated strains. Detection of IS257 next to the glycosyltransferase gene was not observed in all bovine-associated strains. Further studies are needed to identify markers for host adaptation that may have diagnostic value in predicting bacteriological cure after antimicrobial treatment in dairy practice and to explain biological mechanisms behind the association between host adaptation and treatment response.

\section{ACKNOWLEDGMENTS}

This study is part of the 5-year mastitis program of the Dutch Udder Health Centre and was financially supported by the Dutch Dairy Board. The laboratory work of Jan Brinkhof and Ingrid Wiggers (GD Animal Health Service, Deventer, the Netherlands) was highly appreciated by the authors. We gratefully acknowledge Jaap Wagenaar (Faculty of Veterinary Medicine, 
Utrecht University, Utrecht, the Netherlands) for his comments during the design of the study and for performing the mecA analyses.

\section{REFERENCES}

Aires-de-Sousa, M., C. E. S. R. Parente, O. Vieira-da-Motta, I. C. F. Bonna, D. A. Silva, and H. de Lencastre. 2007. Characterization of Staphylococcus aureus isolates from buffalo, bovine, ovine, and caprine milk samples collected in Rio de Janeiro State, Brazil. Appl. Environ. Microbiol. 73:3845-3849.

Alves, P. D. D., J. A. McCulloch, S. Even, C. Le Maréchal, A. Thierry, N. Grosset, V. Azevedo, C. A. Rosa, E. Vautor, and Y. Le Loir. 2009. Molecular characterisation of Staphylococcus aureus strains isolated from small and large ruminants reveals a host rather than tissue specificity. Vet. Microbiol. 137:190-195.

Armand-Lefevre, L., R. Ruimy, and A. Andremont. 2005. Clonal comparison of Staphylococcus aureus isolates from healthy pig farmers, human controls, and pigs. Emerg. Infect. Dis. 11:711714 .

Baba, T., T. Bae, O. Schneewind, F. Takeuchi, and K. Hiramatsu. 2008. Genome sequence of Staphylococcus aureus strain Newman and comparative analysis of staphylococcal genomes: Polymorphism and evolution of two major pathogenicity islands. J. Bacteriol. 190:300-310.

Bae, I. G., G. T. Tonthat, M. E. Stryjewski, T. H. Rude, L. F. Reilly, S. L. Barriere, F. C. Genter, G. R. Corey, and V. G. Fowler Jr.. 2009. Presence of genes encoding the Panton-Valentine leukocidin exotoxin is not the primary determinant of outcome in patients with complicated skin and skin structure infections due to methicillinresistant Staphylococcus aureus: results of a multinational trial. J. Clin. Microbiol. 47:3952-3957.

Barkema, H. W., Y. H. Schukken, and R. N. Zadoks. 2006. Invited review: The role of cow, pathogen, and treatment regimen in the therapeutic success of bovine Staphylococcus aureus mastitis. J. Dairy Sci. 89:1877-1895.

Ben Zakour, N. L., D. E. Sturdevant, S. Even, C. M. Guinane, C. Barbey, P. D. Alves, M. F. Cochet, M. Gautier, M. Otto, J. R. Fitzgerald, and Y. Le Loir. 2008. Genome-wide analysis of ruminant Staphylococcus aureus reveals diversification of the core genome. J. Bacteriol. 190:6302-6317.

Campbell, S. J., H. S. Deshmukh, C. L. Nelson, I. G. Bae, M. E. Stryjewski, J. J. Federspiel, G. T. Tonthat, T. H. Rude, S. L. Barriere, G. R. Corey, and V. G. Fowler. 2008. Genotypic characteristics of Staphylococcus aureus isolates from a multinational trial of complicated skin and skin structure infections. J. Clin. Microbiol. 46:678-684.

Capurro, A., A. Aspán, K. Artursson, and K. Persson Waller. 2010. Genotypic variation among Staphylococcus aureus isolates from cases of clinical mastitis in Swedish dairy cows. Vet. J. doi:10.1016/j.tvjl.2009.05.007.

Cocchiaro, J. L., M. I. Gomez, A. Risley, R. Solinga, D. O. Sordelli, and J. C. Lee. 2006. Molecular characterization of the capsule locus from non-typeable Staphylococcus aureus. Mol. Microbiol. 59:948-960.

Cuny, C., B. Strommenger, W. Witte, and C. Stanek. 2008. Clusters of infections in horses with MRSA ST1, ST254, and ST398 in a veterinary hospital. Microb. Drug Resist. 14:307-310.

de Neeling, A. J., W. J. van Leeuwen, L. M. Schouls, C. S. Schot, A. van Veen-Rutgers, A. J. Beunders, A. G. M. Buiting, C. Hol, E. E. J. Ligtvoet, P. L. Petit, L. J. M. Sabbe, A. J. A. van Griethuysen, and J. D. A. van Embden. 1998. Resistance of staphylococci in the Netherlands: Surveillance by an electronic network during 1989 1995. J. Antimicrob. Chemother. 41:93-101.

Deluyker, H. A., S. N. Van Oye, and J. F. Boucher. 2005. Factors affecting cure and somatic cell count after pirlimycin treatment of subclinical mastitis in lactating cows. J. Dairy Sci. 88:604-614.

Deurenberg, R. H., and E. E. Stobberingh. 2008. The evolution of Staphylococcus aureus. Infect. Genet. Evol. 8:747-763.
Dingwell, R. T., K. E. Leslie, P. Sabour, D. Lepp, and J. Pacan. 2006. Influence of genotype of Staphylococcus aureus, determined by pulsed-field gel electrophoresis, on dry-period elimination of subclinical mastitis in Canadian dairy herds. Can. J. Vet. Res. $70: 115-120$

Dogan, B., Y. H. Schukken, C. Santisteban, and K. J. Boor. 2005. Distribution of serotypes and antimicrobial resistance genes among Streptococcus agalactiae isolates from bovine and human hosts. J. Clin. Microbiol. 43:5899-5906.

Enright, M. C., N. P. J. Day, C. E. Davies, S. J. Peacock, and B. G. Spratt. 2000. Multilocus sequence typing for characterization of methicillin-resistant and methicillin-susceptible clones of Staphylococcus aureus. J. Clin. Microbiol. 38:1008-1015.

Fitzgerald, J. R., W. J. Meaney, P. J. Hartigan, C. J. Smyth, and V. Kapur. 1997. Fine-structure molecular epidemiological analysis of Staphylococcus aureus recovered from cows. Epidemiol. Infect. 119:261-269.

Fitzgerald, J. R., S. R. Monday, T. J. Foster, G. A. Bohach, P. J. Hartigan, W. J. Meaney, and C. J. Smyth. 2001b. Characterization of a putative pathogenicity island from bovine Staphylococcus aureus encoding multiple superantigens. J. Bacteriol. 183:63-70.

Fitzgerald, J. R., D. E. Sturdevant, S. M. Mackie, S. R. Gill, and J. M. Musser. 2001a. Evolutionary genomics of Staphylococcus aureus: Insights into the origin of methicillin-resistant strains and the toxic shock syndrome epidemic. Proc. Natl. Acad. Sci. USA 98:8821-8826.

Graber, H. U., J. Naskova, E. Studer, T. Kaufmann, M. Kirchhofer, M. Brechbühl, W. Schaeren, A. Steiner, and C. Fournier. 2009. Mastitis-related subtypes of bovine Staphylococcus aureus are characterized by different clinical properties. J. Dairy Sci. 92:1442-1451.

Guidry, A., A. Fattom, A. Patel, C. O'Brien, S. Shepherd, and J. Lohuis. 1998. Serotyping scheme for Staphylococcus aureus isolated from cows with mastitis. Am. J. Vet. Res. 59:1537-1539.

Halasa, T., K. Huijps, O. Østerås, and H. Hogeveen. 2007. Economic effects of bovine mastitis and mastitis management: A review. Vet. Q. 29:18-31.

Hasman, H., A. Moodley, L. Guardabassi, M. Stegger, R. L. Skov, and F. M. Aarestrup. 2010. spa type distribution in Staphylococcus aureus originating from pigs, cattle and poultry. Vet. Microbiol. 141:326-331.

Haveri, M., A. Roslöf, L. Rantala, and S. Pyörälä. 2007. Virulence genes of bovine Staphylococcus aureus from persistent and nonpersistent intramammary infections with different clinical characteristics. J. Appl. Microbiol. 103:993-1000.

Herron-Olson, L., J. R. Fitzgerald, J. M. Musser, and V. Kapur. 2007. Molecular correlates of host specialization in Staphylococcus aureus. PLoS ONE 2:e1120.

Ikawaty, R., E. C. Brouwer, M. D. Jansen, E. van Duijkeren, D. Mevius, J. Verhoef, and A. C. Fluit. 2009. Characterization of Dutch Staphylococcus aureus from bovine mastitis using a multiple locus variable number tandem repeat analysis. Vet. Microbiol. 136:277-284.

Jørgensen, H. J., T. Mørk, D. A. Daugant, A. Kearns, and L. M. Rørvik. 2005. Genetic variation among Staphylococcus aureus strains from Norwegian bulk milk. Appl. Environ. Microbiol. 71:8352-8361.

Lalani, T., J. J. Federspiel, H. W. Boucher, T. H. Rude, I. G. Bae, M. J. Rybak, G. T. Tonthat, G. R. Corey, M. E. Stryjewski, G. Sakoulas, V. H. Chu, J. Alder, J. N. Steenbergen, S. A. Luperchio, M. Campion, C. W. Woods, and V. G. Fowler. 2008. Associations between the genotypes of Staphylococcus aureus bloodstream isolates and clinical characteristics and outcomes of bacteremic patients. J. Clin. Microbiol. 46:2890-2896.

Lindsay, J. A., C. E. Moore, N. P. Day, S. J. Peacock, A. A. Witney, R. A. Stabler, S. E. Husain, P. D. Butcher, and J. Hinds. 2006. Microarrays reveal that each of the ten dominant lineages of Staphylococcus aureus has a unique combination of surfaceassociated and regulatory genes. J. Bacteriol. 188:669-676.

Lowder, B. V., C. M. Guinane, N. L. Ben Zakour, L. A. Weinert, A. Conway-Morris, R. A. Cartwright, A. J. Simpson, A. Rambaut, U. 
Nübel, and J. R. Fitzgerald. 2009. Recent human-to-poultry host jump, adaptation, and pandemic spread of Staphylococcus aureus. Proc. Natl. Acad. Sci. USA 106:19545-19550.

Melchior, M. B. 2007. Biofilms: Implications for the therapy of bovine Staphylococcus aureus mastitis. PhD thesis. Utrecht University, Utrecht, the Netherlands.

Middleton, J. R., and L. K. Fox. 2002. Influence of Staphylococcus aureus strain on mammary quarter milk production. Vet. Rec. 150:411-413.

Olsen, J. E., H. Christensen, and F. M. Aarestrup. 2006. Diversity and evolution of blaZ from Staphylococcus aureus and coagulasenegative staphylococci. J. Antimicrob. Chemother. 57:450-460.

Rabello, R. F., B. M. Moreira, R. M. M. Lopes, L. M. Teixeira, L. W. Riley, and A. C. D. Castro. 2007. Multilocus sequence typing of Staphylococcus aureus isolates recovered from cows with mastitis in Brazilian dairy herds. J. Med. Microbiol. 56:1505-1511.

Sandgren, C. H., K. Persson Waller, and U. Emanuelson. 2008. Therapeutic effects of systematic or intramammary antimicrobial treatment of bovine subclinical mastitis during lactation. Vet. J. 175:108-117.

Shook, G. E. 1993. Genetic improvement of mastitis through selection on somatic cell count. Vet. Clin. North Am. Food Anim. Pract. 9:563-581

Sidhu, M. S., E. Heir, T. Leegaard, K. Wiger, and A. Holck. 2002. Frequency of disinfectant resistance genes and genetic linkage with $\beta$-lactamase transposon Tn552 among clinical staphylococci. Antimicrob. Agents Chemother. 46:2797-2803.

Smith, E. M., L. E. Green, G. F. Medley, H. E. Bird, and C. G. Dowson. 2005a. Multilocus sequence typing of Staphylococcus aureus isolated from high-somatic-cell-count cows and the environment of an organic dairy farm in the United Kingdom. J. Clin. Microbiol. 43:4731-4736

Smith, E. M., L. E. Green, G. F. Medley, H. E. Bird, L. K. Fox, Y. H. Schukken, J. V. Kruze, A. J. Bradley, R. N. Zadoks, and C. G. Dowson. 2005b. Multilocus sequence typing of intercontinental bovine Staphylococcus aureus isolates. J. Clin. Microbiol. 43:47374743.

Smyth, D. S., E. J. Feil, W. J. Meaney, P. J. Hartigan, T. Tollersrud, J. R. Fitzgerald, M. C. Enright, and C. J. Smyth. 2009. Molecular genetic typing reveals further insights into the diversity of animalassociated Staphylococcus aureus. J. Med. Microbiol. 58:13431353.

Sol, J., O. C. Sampimon, J. J. Snoep, and Y. H. Schukken. 1997. Factors associated with bacteriological cure during lactation after therapy for subclinical mastitis caused by Staphylococcus aureus. J. Dairy Sci. 80:2803-2808.

Sung, J. M. L., D. H. Lloyd, and J. A. Lindsay. 2008. Staphylococcus aureus host specificity: comparative genomics of human versus animal isolates by multi-strain microarray. Microbiology 154:1949-1959.

van Belkum, A., D. C. Melles, J. K. Peeters, W. B. van Leeuwen, E. van Duijkeren, X. W. Huijsdens, E. Spalburg, A. J. de Neeling, and H. A. Verbrugh. 2008. Methicillin-resistant and -susceptible Staphylococcus aureus sequence type 398 in pigs and humans. Emerg. Infect. Dis. 14:479-483.

van den Borne, B. H. P., G. van Schaik, T. J. G. M. Lam, and M. Nielen. 2010. Therapeutic effects of antimicrobial treatment during lactation of recently acquired bovine subclinical mastitis: Two linked randomized field trials. J. Dairy Sci. 93:218-233.

van Loo, I., X. Huijsdens, E. Tiemersma, A. de Neeling, N. van de Sande-Bruinsma, D. Beaujean, A. Voss, and J. Kluytmans. 2007. Emergence of methicillin-resistant Staphylococcus aureus of animal origin in humans. Emerg. Infect. Dis. 13:1834-1839.

Walther, B., S. Monecke, C. Ruscher, A. W. Friedrich, R. Ehricht, P. Slickers, A. Soba, C. G. Wleklinski, L. H. Wieler, and A. LübkeBecker. 2009. Comparative molecular analysis substantiates zoonotic potential of equine methicillin-resistant Staphylococcus aureus. J. Clin. Microbiol. 47:704-710.

Weese, J. S., and E. van Duijkeren. 2010. Methicillin-resistant Staphylococcus aureus and Staphylococcus pseudintermedius in veterinary medicine. Vet. Microbiol. 140:418-429.

Yazdankhah, S. P., H. Sørum, and H. Oppegaard. 2000. Comparison of genes involved in penicillin resistance in staphylococci of bovine origin. Microb. Drug Resist. 6:29-36.

Zadoks, R., W. van Leeuwen, H. Barkema, O. Sampimon, H. Verbrugh, Y. H. Schukken, and A. van Belkum. 2000. Application of pulsedfield gel electrophoresis and binary typing as tools in veterinary clinical microbiology and molecular epidemiologic analysis of bovine and human Staphylococcus aureus isolates. J. Clin. Microbiol. 38:1931-1939.

Zadoks, R. N., W. B. van Leeuwen, D. Kreft, L. K. Fox, H. W. Barkema, Y. H. Schukken, and A. van Belkum. 2002. Comparison of Staphylococcus aureus isolates from bovine and human skin, milking equipment, and bovine milk by phage typing, pulsedfield gel electrophoresis, and binary typing. J. Clin. Microbiol. 40:3894-3902. 